\title{
RISK ANALYSIS FOR OCCUPATIONAL HEALTH AND SAFETY IN MINING SECTOR
}

\author{
DOI: 10.17261/Pressacademia.2018.899 \\ PAP- V.7-2018(52)-p.285-289
}

\section{Mehmet Colak ${ }^{1}$, Ceren Aygurler ${ }^{2}$, Tahsin Cetin ${ }^{3}$}

${ }^{1}$ Mugla Sitki Kocman University, Technology Faculty, Woodworking Industrial Engineering, 48000, Kotekli Campus, Mugla, Turkey. cmehmet@mu.edu.tr, ORCID: 0000-0003-4780-587X

${ }^{2}$ Mugla Sitki Kocman University, Technology Faculty, Woodworking Industrial Engineering, 48000, Kotekli Campus, Mugla, Turkey. ceren.aygurler@eczacibasi.com.tr, ORCID: 0000-0002-0518-0034

${ }^{3}$ Mugla Sitki Kocman University, Technology Faculty, Woodworking Industrial Engineering, 48000, Kotekli Campus, Mugla, Turkey. tahsincetin@mu.edu.tr, ORCID: 0000-0002-7886-981X

To cite this document

Colak, M., Aygurler, C., Cetin, T. (2018). Risk analysis for occupational health and safety in mining sector. PressAcademia Procedia (PAP), V.7, p.285-289.

Permemant link to this document: http://doi.org/10.17261/Pressacademia.2018.899

Copyright: Published by PressAcademia and limited licenced re-use rights only.

\section{ABSTRACT}

Purpose- The purpose of this study is to determine the necessary precautions to keep the hasards and risks at acceptable levels which can be occurred in term of occupational health and safety in Mining factories by analyzing these dangers and risks.

Methodology- In this study, it was tried to give information about OHSAS 18001 standard and work on risk related to Occupational Health and Work Safety in Mining sector. The risk assessment studies and analyzes were carried out in the mine plant where the application was made.

Findings- The risks identified and the precautions taken according to the analyzes made are stated.

Conclusion- With the OHSAS 18001 system, even small accidents have been reported and studies have been carried out in order to take precautions and it has been shown that the OHSAS 18001 system gives consciousness to employees about preventing such accidents.

Keywords: Risk assessment, OHSAS 18001, occupational health and safety, mining sector.

JEL Codes: I10, I11, LO0

\section{MADENCILIK SEKTÖRÜNDE iş SAĞLIĞI VE GÜVENLiĞi AÇISINDAN RISK ANALiZi}

\section{ÖZET}

Amaç - Bu çalışmanın amacı; Maden Fabrikalarında iş sağlığı ve güvenliği açısından ortaya çıkabilecek tehlike ve riskleri analiz ederek kabul edilebilir seviyelerde tutabilmek için alınması gereken önlemleri belirlemektir.

Yöntem - Bu çalışmada madencilik sektöründe İş Sağlığı ve Güvenliği ile ilgili risk konusunda yapılan çalışmalar ve OHSAS 18001 standardı konusunda bilgi verilmeye çalışılmıştır. Risk değerlendirme çalışmaları ile uygulaması yapılan Maden fabrikasında analizler yapılmıştır. Bulgular- Yapılan analizlere göre tespit edilen riskler ve alınan önlemler belirtilmiştir.

Sonuç- OHSAS 18001 sistemi sayesinde küçük kazaların dahi bildirilerek, tedbir alınması yönünde çalışmalar yapılması ile OHSAS 18001 sisteminin bu tür kazaların önlenmesi konusunda çalışanlarda bilinçlenme sağladığı gösterilmiştir.

Anahtar Kelimeler: Risk değerlendirme, OHSAS 18001, iş sağlığı ve güvenliği, madencilik sektörü.

JEL Kodları: I10, I11, L00

\section{GiRiş}

Dünyada ve Türkiye'de, sanayileşme ve teknolojik ilerlemeye paralel olarak, işyerlerindeki çalışanların güvenliği ile ilgili ortak sorunlar gündeme gelmeye başlamıştır. Gelişen teknolojiyle birlikte çalışanlar, daha önce karşılaşmadıkları yeni risk ve tehlikelerle karşı karşıya kalmaktadır. Başlangıçta fazla önemsenmeyen bu sorunların işletmelerin çalışmasını tehlikeye sokması ve iş verimini olumsuz etkilemesi sonucu, sağlık ve güvenlikle ilgili tedbirlerin alınması gündeme gelmiştir. Her geçen gün iş kazalarıyla maddi ve manevi kayıpların büyük boyutlara ulaşması konunun önemini daha da arttırmaktadır.

Gelişen ve genişleyen teknoloji içinde çalışan, üretken insanların her gün karşılaştıkları konu iş kazalarıdır. Bunlardan korunmak ve kaçınmak, ancak “iş̧̧i Sağlığı ve İş Güvenliği” tedbirlerinin, kurallarının bilinmesi ve uygulanması ile mümkündür. Ülkemizde iş kazaları ve meslek hastalıklarının önüne geçebilmek adına her geçen gün iş sağlığı ve güvenliği çalışmalarına verilen önem artmaktadır. illk bakışta 
meydana gelen kazaların insan odaklı olduğu düşünülse de, bireyin çalışma ortamı, insan-makine, makine-insan adaptasyon gibi etkenler göz önüne alınarak riskli çalışma alanları ve ortamları belirlenerek doğabilecek tehlikeleri irdelemek toplum yararına olacaktır.

İş sağlığı ve güvenliği konusunda yapılan çalışmaların temel taşını risk analizi ve değerlendirmesi oluşturmaktadır. Bu sayede Türk İş Mevzuatını Avrupa normlarına uyumlandırma çabaları, iş dünyasını, iş sağlığı ve güvenliği alanında yeni bir kavramla tanıştırmıştır. Risk Değerlendirme, yasal yükümlülük açısından bakıldığında; 30.06.2012 tarihli 28339 sayılı Resmi Gazete' de yayımlanan 6331 sayılı İ̧ Sağlığı ve Güvenliği Kanunu' nun 10. Maddesinin (1) bendinde "İşveren, iş sağlığı ve güvenliği yönünden risk değerlendirmesi yapmak veya yaptırmakla yükümlüdür." ibaresi yer almaktadır.

Son yıllarda madencilik sektöründe ihracatta büyük bir gelişim kaydeden ülkemizde, maden ocak işletmeciliği ve maden üretim fabrikaları ön sıralarda yer almaktadır. Madencilik faaliyetlerinin çoğunun insan gücüne dayanarak yapıldığı bu alanların iş sağlığı ve güvenliği açısında daha güvenli hale getirilebilmesi için kazalar olmadan risk analizi yapmak, gerek çalışan sağlığı gerekse işveren açısından büyük önem arz etmektedir. Bu çalışma ortamlarında üretim süreçlerini geliştirme ve yöntemlerinin araştırılması konularını irdelemeden, öncelikli yapılması gereken çalışma risk analizi çalışmalarıdır. Risk analizi çalışmaları ışığı altında üretim süreçleri belirlenerek doğabilecek riskler önceden belirlenip bertaraf edilmelidir.

Risk değerlendirme çalışması, işletmelerin çalışma koşulları ve iş adımlarından dolayı oluşabilecek iş kazalarının ve meslek hastalıklarının tespiti için ihtiyaç duyulan önemli bir uygulamadır. İşçilerin sağlığı ve iş güvenliği için mevcut tehlikelerin tespit edilmesi, tehlikelerin giderilmesi ve güvenli bir çalışma ortamının sağlanabilmesi için risk değerlendirme gerekli olan bir çalışmadır. Risk değerlendirme çalışması için çok farklı yöntemler bulunmaktadır. Her yöntem her işletmenin risk analizi için uygun olmayabilir. Amaç, işletmeye en uygun risk değerlendirme metodunun tespit edilip uygulanmasıdır. Tehlikelerin ve risklerin analizi için daha iyi nasıl yapabilirim sorusuyla yola çıkılmalı ve riskleri en gerçekçi tespit eden yöntemler ile risk değerlendirme çalışması yapılmalıdır.

Bu çalışmanın amacı; Maden Ocakları ve Üretim Fabrikalarında iş güvenliği açısından ortaya çıkabilecek tehlike ve riskleri analiz ederek kabul edilebilir seviyelerde tutabilmek için alınması gereken önlemleri belirlemektir. Aynı zamanda bu çalışma, İş Sağlığı ve Güvenliği kavramı hakkında bilgi vermek, bu kavramın madencilik sektöründeki uygulamaları hakkında ışık tutmaktır.

\section{LITERATÜR INCELEMESI}

İş Sağlığı ve Güvenliğinin önemi, Avrupa ülkelerinde çok eski tarihlerden itibaren bilindiği için bu ülkelerde bu konuda yapılan çalışmalar çok daha fazladır. Türkiye'de isG'nin iş hayatında önemli bir yere sahip olduğu bilinci, 2003 yılında çıkarılan İş Kanunu'nda i̇ş Sağlığı ve Güvenliği'ne yer verilmesiyle oluşmuştur. İş Sağlığı ve Güvenliği koşullarının sağlıklı bir şekilde yerine getirilmesi ve iş kazaları ile meslek hastalıklarının önlenmesi için Risk Değerlendirmesi yapılması gerekmektedir. Dolayısıyla 2003 yılından itibaren; İş Sağı̆ğı ve Güvenliği ile Risk Değerlendirmesi konusunda yapılan çalışmaların sayısı 2003 yılı öncesine bakıldığında oldukça fazladır.

Kasap ve Subaşı (2011), tarafından yapılan çalışmada açık işletme madenlerinde farklı meslek gruplarında çalışanların hangi tür tehlikelere daha fazla maruz kaldıklarının belirlenmesi ile tehlikeler karşısında iş kazası geçirme veya meslek hastalığına yakalanma risklerinin denetim altına alınmasında AHP yönteminin kullanılabileceği, Türkiye Kömür İşletmeleri (TKi) kurumuna bağlı Garp Linyitleri işletmesinden alınan veriler ile uygulamalı olarak açıklanmıştır. Önder S., Mutlu M. ve Önder M. (2011) tarafından yapılan çalışmada, SLi işletmesinde 2003-2008 yılları arasında meydana gelmiş olan yaralanmalı iş kazaları incelenerek, öncelikle kaza sıklık oranları (KSO), kaza ağırlık oranları (KAO) ve kaza olabilirlik oranları (KOO) hesaplanacak yıllar arası karşılaştırmalar yapılmıştır. İş kazaları neden, yer, uzuv ve sanata göre gruplanarak, $5 \times 5$ 'lik risk değerlendirme karar matrisi yöntemi kullanılarak incelenmiş ve daha sonra, tüm parametrelerin risk skorları ve risk grupları belirlenmiştir. Karadağ (2000) tarafından Ankara ilinde bulunan 3 taş ocağı ile 2 kum ocağının ve çalışanlarının işçi sağığı ve iş güvenliği açısından değerlendirilmesi konulu bir çalışma yapılmıştır. Bu çalışmada; söz konusu ocak sahalarında çalışan işçiler ile görüşülmüş ve sağlık taramaları yapılarak değerlendirmede bulunulmuştur. İnsanlık tarihinin başlangıcından itibaren insanlar, kendi sağlıklarını ve yaşamlarını tehlikeye sokan işlerde çalışmışlar, günün koşullarına göre gerekli korunma önlemlerini arama çabası içinde olmuşlardır (Durmuşoğlu, 2008).

Yukarıda anlatılan çalışmalar, iş sağlığı ve güvenliği bilincinin ülkemizde son yıllarda daha çok arttığını göstermektedir. İs sağlığı ve güvenliği çalışmalarının beyni olarak nitelendirilen risk değerlendirme çalışmaları için kullanılan değişik metotlar ve uygulamalar olduğu görülmektedir. Yapılan bu çalışmaların, günlük hayatta iş sağlığı ve güvenliği çalışmaları için bir yol haritası görevi görmesi istenmektedir.

Bu çalışmayla madencilik sektöründe yapılan Risk Değerlendirme çalışmaları, İş Sağlığı ve Güvenliği, Risk Değerlendirmesi ve Madencilik sektöründe Risk Değerlendirme üzerine yapılan çalışmaların uygulama kısımlarının bulgu ve sonuç kısımları aktarılacaktır.

\section{VERI VE YÖNTEM}

Risk analizi metedolojileri, risk analizi sürecinin matematiksel işlemle ve yorumlarının yapıldığı çekirdek kısmıdır (Özkılıç, 2005). Risk değerlendirmesinin amacı; "Tehlikeler nelerdir? , Potansiyel etki ve sonuçlar nelerdir ve bunlar kabul edilebilir midir? , Bu etki ve sonuçların meydana gelme olasılıkları nedir? ve riskin kabul edilebilir durumunun devam ettirilmesi için kontrol ve koruma çalışmaları yeterli mi?" sorularına cevap vermektir.

Risk değerlendirmesinin hedefleri aşağıdaki gibidir:

- Operasyonun, çalışanlar ve çevre açısından, güvenlik ve sağlıklarının hangi derecede sağlandığının kanıtlanabilir biçimde belirlenmesi,

- Güvenlik gereksinimlerine uygunluğunun doğrulanması, teyit edilmesi,

- Herhangi bir hata oluştuğunda, bunun mal, can ve çevreye etkilerinin belirlenmesi,

- Bu hataların nasıl değerlendirileceğinin belirlenmesi,

- Bu hataların nasıl kontrol altına alınabileceğinin tespitidir (Özkılıç, 2005). 


\section{$>\quad$ RISK $=$ ŞANS $\times$ FREKANS $\times$ ŞiDDET}

Bu formül neticesinde risk değeri; 400'den büyük çıkarsa risk tolerans gösterilemezdir ve hemen gerekli önlemler alınmalı veya tesis, bina, çevrenin kapatılması düşünülmelidir. 400 ile 200 arasında çıkarsa risk esası risktir ve kısa dönemde iyileştirilmelidir(birkaç ay içinde). 200 ile 70 arasında çıkarsa risk önemli risktir ve uzun dönemde iyileştirilmelidir (yıl içinde). 70 ile 20 arasında ise risk olası risktir ve gözetim altında tutulmalıdır. 20’den küçük ise risk önemsiz risktir ve önlem öncelikli değildir (Şardan, 2005).

Risk değerlendirmesi ve analizi yapılan firma; seramik fabrikalarına hammadde temini amacı ile 1978 yılında kurulmuştur. Bugün Türkiye'nin önde gelen endüstriyel mineral ve metalik maden üretici ve ihratçılarındandır. Sürdürülebilir bir çevre için karbon salınımının azaltılması amacıyla yenilenebilir kaynakların kullanımının artıııması yolunda çalışmalar yapan firma, stok sahasındaki enerji ihtiyacını karşılamak üzere bölgedeki en yüksek kurulu güce sahip çatı üzeri lisanssız güneş enerjisi santralini, farkı tesiste de Türkiye'nin öz tüketim amaçlı en büyük güneş enerjisi santralini kurmuştur. İki tesisteki Güneş Enerjisi Santralleri ile yılda yaklaşık 2 milyon tondan fazla karbon salınımın engellenmesi öngörülmektedir.

Firma başta seramik sanayi olmak üzere, kaynak elektrod, cam, refrakter, emaye aşındırıcı, izolasyon, boya, plastik, inşaat, çimento, kompoze taş, demir-çelik, döküm, rutil, zirkonyum silikat, titanyum oksit, silikon karbit ve kalsine alumina öncelikli olmak üzere 150 'den fazla ürün grubu ile hizmet sunmaktadır.

Risk değerlendirme çalışması için çok farklı yöntemler bulunmaktadır. Her yöntem her işletmenin risk analizi için uygun olmayabilir. Amaç, işletmeye en uygun risk değerlendirme metodunun tespit edilip uygulanmasıdır. Tehlikelerin ve risklerin analizi için daha iyi nasıl yapabilirim sorusuyla yola çıkılmalı ve riskleri en gerçekçi tespit eden yöntemler ile risk değerlendirme çalışması yapılmalıdır.

Bu çalışma, madencilik sektöründe feldspat işletmeciliği yapan firmalarda risk değerlendirmesi çalışmasının verimli ve riskleri minimize edecek şekilde yapılması düşüncesiyle gerçekleştirilmiştir.

\section{BULGULAR}

Firmanın tesis ve ocaklarındaki tehlike değerlendirme ve risk analizi Kinney Metoduna göre analiz edilmiştir. Oluşabilecek tehlikeler aşağıdaki şekilde analiz edilmiştir:

•Kayma, takılma ve benzeri nedenlerle düşme, Yüksekten düssme, Cisimlerin düşmesi, Toz, Gürültü ve Titreşim, Uygun olmayan duruş ve çalışma şekilleri, Seyyar el aletleri kullanımı, Sabit makine tezgâh kullanımı, Hareketli makine ekipmanları, Elle taşıma işleri (Ergonomik zorlama), Elektrik ve elektrikli aletlerle çalışma, Aydınlatma, Basınçı kaplar, Kompresör tankı, İş yeri yerleşim planı, Ürünler ve atıklar, Mekanik kaldırma araçları, Motorlu araçların kullanımı ve taşımacııı, İstenmeyen insan davranışları (Dikkatsizlik, yorgunluk, öfke) Vardiyalı çalışmadan kaynaklı vücut düzensizliği, Yangın, parlama ve patlama.

\section{Tehlike değerlendirme ve risk analiz tablolarına göre risk görülen yerler gösterilmiştir.}

İncelenen madencilik fabrikasında görülen başlıca tehlike ve riskler aşağıda sıralanmıştır.

Alınması gereken tedbirler;

- Yapılan gözlem ve incelemelerde ortamdaki gürültü sebebiyle gürültü ölçümleri yapılmalı.

- Firmadaki madencilik faaliyeti sebebi ile ortamda oluşan tozlar en aza indirgenecek şekilde önlemler alınmalı.

- Çalışma sahası içerisinde makinelerden kaynaklanan titreşim ölçüm analizleri değerlendirilmeli.

- Vinç kullanan ehliyetli personel sayısı yetersizdir. İşletme içerisinde korkuluk ve basamakların tamamlanması planlanmışıı.

- Döner akşamların kapatılması önceliklidir.

- İşletmedeki çukurların veya düzensiz yerleşimin personel güvenliği ön planda tutularak düzenleyici faaliyetlerin yapılması gerekmektedir.

Incelenen madencilik fabrikasında tespit edilen ve kabul edilebilir seviyelerin üzerinde olan tehlikeler;

- Fabrika içerisinde kişisel koruyucu donanımlar kullanılmakta fakat gürültü ölçümü güncel olarak yapılmadığından hali hazırda kullanılan kulak koruyucularının gürültü seviyelerine göre uygunluğu tespit edilememiștir.

- Yapılan inceleme ve gözlemlerde üretim sahası içerisinde maske kullanımının yaygın olduğu görülmüş ancak ortam güncel toz ölçüm haritalarına göre yapılmadığından kullanılan maskelerin uygunluğu tespit edilememiştir.

- Makineler üzerinde titreşim ölçümü yapılmamışır. Bu konuda çalışma yapılması planlanmıştır.

- Vinç kullanan ehliyetli personel sayısı yetersiz olduğundan 15 personele daha vinç ehliyeti alınmalıdır.

- Kullanılmış sanayi yağları geri dönüşüm firmaları ile irtibata geçip geri dönüşümü sağlanmalıdır. 
Tablo 1: Risk Değerlendirme Değer Tablosu

FINE-KINNEY / RISK DEG̈ERI VE IŞLEMLER

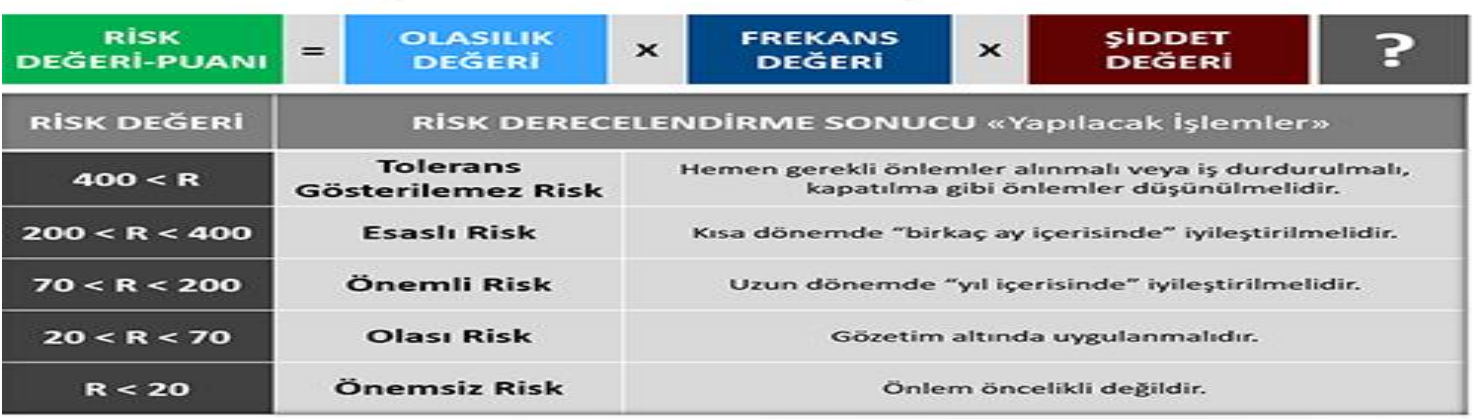

Tablo 2: Düzeltici Önleyici Faaliyetler Analizi

\begin{tabular}{|c|c|c|c|}
\hline isG UYGUNSUZLUK TESPіті & $\begin{array}{l}\text { RISK DERECELENDIRME } \\
\text { Olasılık-Şiddet-Frekans } \\
\text { (OxŞxF) İşlem Öncesi }\end{array}$ & ÖNLEYICi & $\begin{array}{l}\text { RiSK DERECELENDiRME } \\
\text { Olasılık-Şiddet-Frekans } \\
\text { (OxŞxF) İşlem Sonrası }\end{array}$ \\
\hline $\begin{array}{l}\text { K-61 kırıcı motorunun kayış kasnak } \\
\text { koruması standart hale getirilmeli. }\end{array}$ & 1x15x6 (Önemli Risk) & $\begin{array}{lll}\text { Kasnak kayış koruması } \\
\text { yapıldı. }\end{array}$ & 0,1×15x6 (Önemsiz Risk) \\
\hline $\begin{array}{l}\text { Tek elek besleme bandı ucunda platform } \\
\text { olmadığından dolayı personelin } \\
\text { korkuluğun üzerine çıkıp geçmesi. }\end{array}$ & 3×40x3 (Esaslı Risk) & $\begin{array}{l}\text { Bölge genişletilerek geçiş } \\
\text { alanı yapıldı. }\end{array}$ & 0,2×40x3 (Olası Risk) \\
\hline $\begin{array}{l}\text { Tek elek motor şaft korumasının } \\
\text { olmaması. }\end{array}$ & 1x40x3 (Önemli Risk) & Açık döner aksam kapatıldı. & 0,2×40x3 (Olası Risk) \\
\hline Elek şaftlarının açık olması. & 1x15x6 (Önemli Risk) & $\begin{array}{l}\text { Elek şaftlarına döner aksam } \\
\text { koruması yapıldı. }\end{array}$ & 0,2×15x6 (Önemsiz Risk) \\
\hline $\begin{array}{l}\text { Bunkerin beslenmesi sırasında trapez } \\
\text { saclara malzeme çarpması. }\end{array}$ & 1x15x6 (Önemli Risk) & $\begin{array}{l}\text { Bunker trapez sacları } \\
\text { çevresine koruma amaçlı sac } \\
\text { yapıldı. }\end{array}$ & 0,5×15x6 (Olası Risk) \\
\hline $\begin{array}{l}\text { Susuzlaştırma elek üzeri yürüme } \\
\text { platformundaki besleme kutusunun } \\
\text { yürüme yolunu kapatması. }\end{array}$ & 1×15x6 (Önemli Risk) & Yolun güzerğahı değiştirildi. & 0,2×15x6 (Önemsiz Risk) \\
\hline $\begin{array}{l}\text { Ara ürün-2 vakum pompası yanındaki } \\
\text { çıkışın yetersiz genişlikte olması. }\end{array}$ & 3x7x6 (Önemli Risk) & Çıkış noktası düzenlendi. & 0,2×7x6 (Önemsiz Risk) \\
\hline $\begin{array}{l}\text { GG bunkerinden bigbag dolumu yapılırken } \\
\text { kullanılan platformun alt bölgesinde } \\
\text { korkuluk ve merdiven çıkışında basamak } \\
\text { olmaması }\end{array}$ & 3×7x6 (Önemli Risk) & $\begin{array}{l}\text { Eksik korkuluk ve basamak } \\
\text { tamamlandı. }\end{array}$ & 1x7x6 (Olası Risk) \\
\hline $\begin{array}{l}\text { Silo altından bigbag dolumu yapılırken } \\
\text { kullanılan platformun korkuluklarının } \\
\text { eksik olması. }\end{array}$ & 3×7x6 (Önemli Risk) & $\begin{array}{l}\text { Eksik korkuluklar } \\
\text { tamamlandı. }\end{array}$ & 1x7x6 (Olası Risk) \\
\hline $\begin{array}{l}\text { Yürüme platformu ile reaktif tankları } \\
\text { arasında bulunan boşluklar. }\end{array}$ & 1x15x6 (Önemli Risk) & $\begin{array}{l}\text { Tanklar ve platformlar arası } \\
\text { boşluklar kapatıldı. }\end{array}$ & 0,5×15x6 (Olası Risk) \\
\hline $\begin{array}{l}\text { Asetat tankının kapak etrafındaki sacların } \\
\text { çürük olması ve buna bağlı olarak kapağın } \\
\text { kapatılamaması. }\end{array}$ & 3×15x3 (Önemli Risk) & $\begin{array}{l}\text { Saclar değiştirilerek yeni } \\
\text { kapak yapıldı. }\end{array}$ & 0,2×15x3 (Önemsiz Risk) \\
\hline $\begin{array}{l}\text { Selüllerin döner aksam korumalarının } \\
\text { olmaması. }\end{array}$ & $\begin{array}{l}3 \times 15 \times 10 \text { (En kısa sürede } \\
\text { giderilecek risk) }\end{array}$ & $\begin{array}{l}\text { Selül kenarı döner aksamlar } \\
\text { kapatıldı. }\end{array}$ & 0,2×15x10 (Olası Risk) \\
\hline $\begin{array}{l}\text { NGG bandı sonundaki döner aksamın açık } \\
\text { olması ve personelin bant sonuna } \\
\text { geçerken motor ve korkuluk üzerinden } \\
\text { geçmes. }\end{array}$ & $\begin{array}{l}6 \times 40 \times 3 \text { (En kısa sürede } \\
\text { giderilecek risk) }\end{array}$ & $\begin{array}{l}\text { Döner aksam kapatılarak } \\
\text { ilave platform yapıldı. }\end{array}$ & 0,5x40x3 (Olası Risk) \\
\hline
\end{tabular}

\section{SONUÇ}

Yukarıdaki Tablo 1-2'de belirtilen düzeltici önleyici faaliyetler analizi olarak önemli derecede risk tehlike olasılık derecelerinin düştüğünü göstermektedir. Yöneticilerin ve işyeri sahiplerinin iş güvenliği konusuna gereken ilgiyi göstermesi, iş sağlığı ve güvenliği konusunda yeterli bilgiye sahip olmaları ve konuya gerekli özeni göstermeleri; ayrıca çalışanların güvenli davranış sergilemelerini teşvik edecek önemli ortamlar şartlar sağlanması gereklidir. Madencilik fabrikalarında genel olarak taşıma, istifleme ve ambalajlama işleri el ile yapıldığından işletme çalışanları, elle taşıma işleri yönetmeliği çerçevesinde eğit verilmeli ve uygulana bilir alanlarda otomasyon sistemine geçilerek olası 
iş kazaları ve meslek hastalıklarının önüne geçilmelidir. Üretim hatlarında kullanılan kimyasallar hakkında çalısanlar bilgilendirilmeli malzeme güvenlik bilgi formları kullanım alanlarına ve gerekli yerlere asılmalıdır.

\section{KAYNAKLAR}

Durmuşoğlu, P. Ö. (2008). Türkiye ve Avrupa Birliğinin işçi sağliği ve iş güvenliği açisindan karşilaştırılması. Gazi Üniversitesi, Sağlık Bilimleri Enstitüsü, Yüksek Lisans Tezi, Ankara.

Kasap, Y., Subaşı E. (2011). Analitik hiyerarşi prosesi ile açik işletme madenciliğinde risk denetimi. Maden İşletmelerinde Iş̧̧i Sağlığı ve iş̧ Güvenliği Sempozyumu Bildiriler Kitabı, Zonguldak.

Karadağ, K. Ö. (2000). Ankara ilinde üç taş ocaği ile iki kum ocağinin ve çalişanlarinin iş̧̧i sağliği ve iş güvenliği açisindan değerlendirilmesi. Hacettepe Üniversitesi Sağlık Bilimler Enstitüsü Bilim Uzmanlı̆̆ı Tezi, Ankara.

Önder, S., Mutlu, M., Önder, M. (2011). Açık işletme kömür madenciliğindeki iş kazalarinin risk değerlendirme karar matrisi ile değerlendirilmesi. Maden İşletmelerinde İş̧i Sağlığı ve iş Güvenliği Sempozyumu'2011 Bildiriler Kitabı, 24-25 Kasım 2011,155-162, Zonguldak.

Şardan, H. S. (2005). İ̧̧ sağliği ve güvenliğinde yeni oluşumlar; risk değerlendirmesi ve OHSAS 18001, Yüksek Lisans Tezi, Gazi Üniversitesi Sosyal Bilimler Enstitüsü, Ankara.

Özkiliç, Ö. (2005). İ̧s sağliği ve güvenliği yönetim sistemleri ve risk değerlendirme metodolojileri. TiSk Yayınları, Ankara. 